\title{
Occurrence of ent-Sesquiterpene in the Japanese Moss-Plagiomnium acutum: First Isolation and Identification of the ent-Sesqui- and Dolabellane-type Diterpenoids from the Musci
}

\author{
Masao Toyota, Kyoko Kimura, and Yoshinori Asakawa* \\ Faculty of Pharmaceutical Sciences, Tokushima Bunri University, Yamashiro-cho, Tokushima 770-8514, Japan. \\ Received June 26, 1998; accepted July 28, 1998
}

The ether extract of the Japanese moss Plagiomnium acutum was chromatographed on silica gel and Sephadex LH-20 to give ent- $\beta$-cedrene and 3,7-dolabelladiene-18-ol which has been isolated from brown algae. To the authors' knowledge, this is the first isolation and identification of sesquiterpenoids from the Musci and the first record of ent- $\beta$-cedrene from the plant kingdom.

Key words Plagiomnium acutum; moss; ent- $\beta$-cedrene; sesquiterpenoid; 3,7-dabelladien-18-ol; dolabellane-type diterpene

The bryophytes are taxonomically placed between the algae and the pteridophytes and more than 20000 species are known in the world. They are divided into three classes, Musci (mosses, 14000 species), Hepaticae (liverworts, 6000 species), and Anthocerotae (hornworts, 300 species).

Many bryophytes have been used as medicinal plants in China, Europe, and North America to cure cuts, burns, external wounds, convulsions, bacteriosis, scalds, urocystitis, tympanitis, neurasthenia, fractures, pulmonary tuberculosis, etc. ") Some bryophytes have an intensely pungent and bitter taste, induce allergenic contact dermatitis, and inhibit the growth of microorganisms. We have been interested in the biological activity of bryophytes and continued to study their chemical constituents. ${ }^{2,3)}$ Among the bryophytes, the chemical constituents of the Hepaticae have been investigated in more detail, because liverworts possess cellular oil bodies which comprise mono-, sesqui-, and diterpenoids and lipophilic aromatic compounds, while the other two classes contain no oil bodies. More than 750 terpenoids, excluding the triterpenoids and carotenoids, and 220 aromatic compounds, excluding the flavonoids, have been isolated from or detected in the Hepaticae. ${ }^{2,3)}$ On the contrary, only three monoterpene hydrocarbons have been detected in the mosses or Splachnum species and only one kaurane-type diterpene isolated from Saelania moss. ${ }^{3)}$ No sesquiterpenoids have been detected in or isolated from the Musci. ${ }^{3}$

Some species belonging to the Mniaceae mosses show hemostatic activity and induce allergenic contact dermatitis. ${ }^{1)}$ In order to isolate such biologically active substances from mosses, we started to study the chemical constituents of the Japanese Plagiomnium acutum. Surprisingly, this moss biosynthesizes ent-sesquiterpene hydrocarbons and a dolabellane-type diterpene alcohol. Here we report the isolation and identification of these terpenoids.

A air-dried $P$. acutum $(10.5 \mathrm{~g})$ was extracted with ether to obtain the crude extract $(160 \mathrm{mg})$. A small amount of the crude extract was analyzed by GC-MS to detect three sesquiterpene hydrocarbons, $\alpha$ - and $\beta$-cedrenes and $\alpha$-acoradiene. The remaining extract was further chromatographed on silica gel and Sephadex LH-20 to afford ent- $\beta$-cedrene $(1 \mathbf{a})^{4)}(13.3 \mathrm{mg})$ and (+)-dolabella-3,7-dien-18-ol (2) $(10.0 \mathrm{mg})$. The structures of $1 \mathrm{a}$ and 2 were established by $600-\mathrm{MHz}{ }^{1} \mathrm{H}$ - and $150-\mathrm{MHz}{ }^{13} \mathrm{C}-\mathrm{NMR}$ spectra including 2D-

* To whom correspondence should be addressed spectra ( ${ }^{1} \mathrm{H}-{ }^{1} \mathrm{H}, \mathrm{HMQC}, \mathrm{HMBC}$, NOESY), IR, EI-MS (high resolution) and comparison of the spectral data with those of an authentic sample (for $\beta$-cedrene) and reference data (for $\beta$-cedrene ${ }^{4)}$ and dolabella-3,7-dien-18-ol ${ }^{5)}$ ). The absolute configuration of $\beta$-cedrene was established as follows. Commercially available (+)- $\beta$-cedrene (1b)-rich oil was chromatographed on silica gel impregnated with silver nitrate to give (+)- $\beta$-cedrene (1b) $\left(\right.$ lit. $\left.^{4)}+9.7\right)$. The same compound isolated from the moss showed $[\alpha]_{D}-10.9$. Upon co-injection of $\mathbf{1 a}$ and $\mathbf{1 b}$ into a capillary column (DB-17; $30 \mathrm{~m} \times 0.25 \mathrm{~mm}$ i.d., film thickness $0.25 \mu \mathrm{m}$ ) one peak appeared on the total ion chromatogram. However, when both compounds were co-injected into a chiral capillary column ( $\beta$-DEX 120; $30 \mathrm{~m} \times 0.25 \mathrm{~mm}$ i.d., film thickness $0.25 \mu \mathrm{m}$ ), two well-separated peaks appeared on the total ion chromatogram (Fig. 1). Thus it is clear that $\beta$-cedrene isolated from the moss is the enantiomer of that obtained from commercial oil. $\beta$-Cedrene has also been detected in the liverwort Bazzania stolonifera, ${ }^{6)}$ although, its absolute configuration

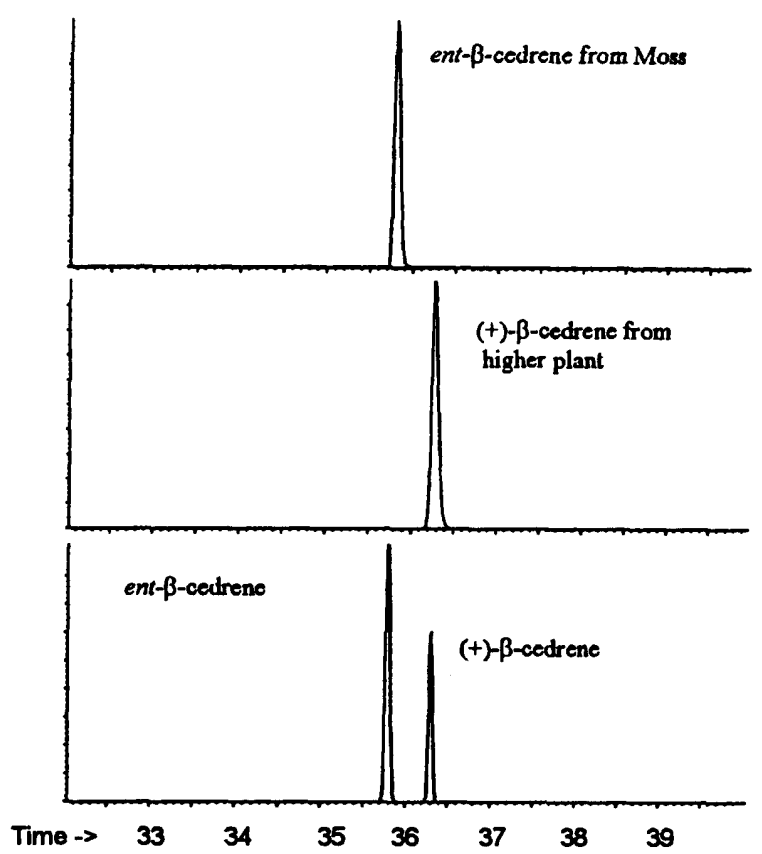

Fig. 1. Total Ion Chromatograms of $(+)$ - and ent- $\beta$-Cedrenes, and the Coinjected Both Enantiomers 


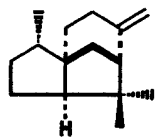

$1 a$

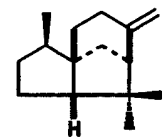

$1 \mathrm{~b}$

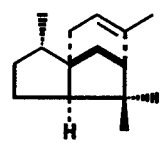

$1 c$

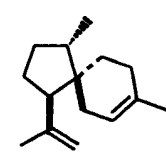

1d

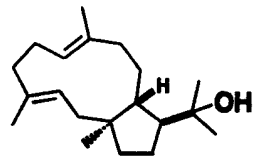

2

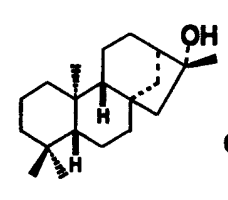

3

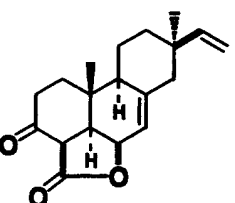

4

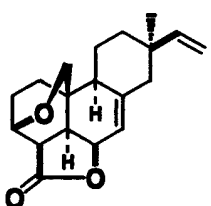

5

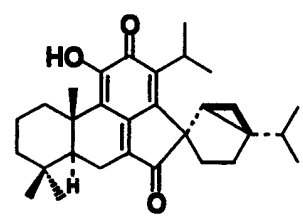

6

Chart 1

remained to be clarified. $\alpha$-Cedrene (1c) and $\alpha$-acoradiene (1d) detected by GC-MS might be the same enantiomers as those found in higher plants, since ent- $\beta$-cedrene (1a) coexisted within the present species. This is the first known isolation and identification of ent-sesquiterpenoid from the Musci. As far as we are aware, it is also the first record of ent- $\beta$-cedrene from the plant kingdom. The dolabellane-type diterpenoid 2 from the moss showed positive optical rotation $[\alpha]_{D}+23.7$ which was almost identical to that $\left([\alpha]_{D}+27.5\right)$ of the same compound isolated from the brown algae Dictyota dichotoma. ${ }^{5)}$ The occurrence of dolabellane-type diterpenoids is very rare in organisms. From the digestive gland of the opisthobranch mollusc Dolabella californica, 14 dolabellane-type diterpenoids have been isolated and their relative stereochemistries established by Ireland and Faulkner. ${ }^{7)}$ The brown algae Dictyota species are the plant source of dolabellanes. ${ }^{5)}$ The dolabellanes are distributed in the Jungermannales liverworts, Barbilophozia, Odontoschisma, and Pleurozia species. ${ }^{3)}$ This is the first isolation of dolabellane diterpenoids from the moss. Only one diterpene, ent-16 $\beta$-hydroxykaurane (3), has been isolated from the exudate of the moss Saelania glaucescens. ${ }^{8)}$ The presence of three other diterpenes, momilactones A (4) and B (5) and chamaecydin (6), have orally been reported from mosses, ${ }^{9)}$ althuogh, their details have not been reported in published papers.

The present four terpenoids are previously known compounds, except for ent- $\beta$-cedrene (1a). However, these results have a significant meaning from the morphological and taxonomic viewpoints of mosses. The Hepaticae contain oil bodies which are responsible for lipophilic mono-, sesqui-, and diterpenoids as well as lipophilic aromatic compounds and $80 \%$ of the isolated sesquiterpenes are the enantiomers of those found in higher plants. These terpenoids and their absolute configurations are very important markers for classification of the Hepaticae. ${ }^{2,3)}$ It is noteworthy that the present moss is chemically very similar to some liverworts because it produces ent-sesqui- and dolabellane-type diterpenoids, although the two plants are morphologically quite different. There is no doubt that our moss sample was pure because we collected the mat of this plant from a location where neither other liverworts nor mosses grow. There are 18 Plagiomnium species in Japan. ${ }^{10)}$ The present compounds might be significant chemical markers of Plagiomnium species. We will attempt to analyze the chemical constituents of the other Plagiomnium species to determine whether further sesqui- and diterpenoids are detected in or isolated from this genus.

Acknowledgments We thank Dr. Zennosuke Iwatsuki (Hattori Botanical Laboratory, Okazaki branch office, Aichi, Japan) for kindly identifying the moss and valuable discussion. This work was supported in part by a Grant-in-Aid for Scientific Research (No. 084459026, B 1996-1998) from The Ministry of Education, Science, Sports and Culture of Japan.

\section{References and Notes}

1) Asakawa Y., "Bryophytes: Their Chemistry and Chemical Taxonomy," ed. by Zinsmeiseter H. D., Mues R., Clarendon Press, Oxford, 1990, pp. $369-410$.

2) Asakawa Y., "Progress in the Chemistry of Organic Natural Products," Vol. 42, ed. by Herz W., Grisebach H., Kirby G. W. , Springer, Vienna, 1982, pp. $1-285$.

3) Asakawa Y., "Progress in the Chemistry of Organic Natural Products," Vol. 65, ed. by Herz, W., Kirby, G. W., Moore, R. E., Steglich, W., Tamm Ch., Springer, Vienna, 1995, pp. 1-562.

4) Acharya S. P., Brown H. C., J. Org. Chem., 35, 196-206 (1970).

5) Amico V., Currenti R., Oriente G., Piattelli M., Tringali C., Phytochemistry, 20, 848-849 (1981).

6) Spörle J., Ph. D. Thesis (Universität des Saarlandes), p. 15 (1990).

7) Ireland C., Faulkner D. J., J. Org. Chem., 42, 3157-3162 (1977).

8) Nilsson E., Martensson M., Acta Chem. Scand., 25, 1486-1487 (1971).

9) Nozaki H., Hamazaki K., Nishimura N., Udaka H., Takashima N., Takaoka D., Abstracts of Papers, The 15th International Botanical Congress, Yokohama, Japan, August 1993, p. 370.

10) Iwatsuki Z., "Catalog of the Mosses of Japan," Hattori Botanical Laboratory, Nichinan, Miyazaki, Japan, 1991, pp. 1-182. 